\title{
Situación económica y militar de Argentina entre 1852 y el inicio de la guerra del Paraguay
}

\author{
Situação econômica e militar da Argentina entre 1852 e 0 início da guerra do Paraguai \\ Economic and military situation in Argentina between 1852 and the beginning of \\ the war in Paraguay
}

Sergio Fernando Sánchez

\section{Resumen}

El texto en general aborda el análisis de la situación financiera, económica y militar entre 1852 y el inicio de la guerra del Paraguay. Del análisis resulta una situación desfavorable para la participación de Argentina en la guerra. Hipótesis que se valida a partir del análisis de los principales eventos financieros y militares que caracterizaron al período objeto de estudio. La argumentación comienza con una breve presentación del Estado de Buenos Aires, continúa con la identificación de la deuda que generaron y trasladaron el gobierno nacional en 1862. Evalúa los alcances del pacto fiscal constitucional de 1853, la reforma constitucional de 1860, y la situación económica respecto de las cuentas nacionales a partir de 1862 . Finalmente, expone la situación militar, desde Pavón hasta la organización del Ejército Nacional de Campaña que se empeñó en el teatro de operaciones del Paraguay.

Palabras clave: Situación económica. Situación militar. Estado nacional.

Coronel/Magister Sergio Fernando Sánchez; Magister en Economía por la Universidad Católica de Cuyo, Magister en Historia de la Guerra por la Escuela Superior de Guerra del Ejército Argentino y Especialista en Gerenciamiento por Resultado y Control de Gestión por la Facultad de Ciencias Económicas de la Universidad de Buenos Aires. Miembro adherente del Instituto de Historia Militar Argentina y doctorando en Historia en la Universidad Torcuato Di Tella.

Recebido em 25/03/2015 - Aprovado em 02/06/2015 http://dx.doi.org/10.5335/hdtv.15n.2.5646 


\section{Introducción}

Antes de entrar en tema, necesito aclarar que mis aportes son realizados como parte de una investigación en curso de mayor amplitud. El recorte temporal como las dimensiones de interés constituyen una excelente ocasión para profundizar sobre el período y formular renovadas preguntas sobre la conveniencia de la Argentina de participar en la guerra del Paraguay, cuando el esfuerzo principal estuvo orientado hacia la organización nacional.

El tema central del texto esta focalizado al análisis de las finanzas públicas, la economía y el poder militar previo al inicio de la guerra del Paraguay. La pregunta central que se encuentra como telón de fondo del presente análisis es cómo se consiguió constituir un Estado nacional con monopolio del ejercicio de la coerción, con finanzas nacionales ordenadas y una moneda de valor constante con alcance a todo el territorio; partiendo de un orden político, económico y social sustentado de un conjunto de estados provinciales autónomos, con reglas de juego diferenciadas, con autoridades, leyes, finanzas y ejércitos propios; es decir, un sistema político que bien puede ser denominado como caudillista.

Configuración política que acusó una ruptura radical con los sistemas políticos previos a la batalla de Caseros. Si bien el nuevo proceso político no estuvo exento de complicaciones; con el triunfo en Pavón, Buenos Aires reinstaló su modelo político y económico de filiación liberal - mercado abierto, competitivo, con una justicia común sujeta a leyes escritas, entre otras particularidades.
La hipótesis que informa el presente texto es la de una Argentina, con sus instituciones, sus finanzas públicas y su instrumento militar en un estado de debilidad tal que no hacía conveniente su participación en la guerra del Paraguay. Es decir, el gobierno de Mitre transitaba la primera mitad del mandato, con un estado financiero caracterizado por la escasez de recursos, una deuda enorme que consumía la casi totalidad de la renta nacional, una economía en lento crecimiento, un Ejército que en enero de 1864 se redujo de 10.200 a 6.000 efectivos, y un mercado monetario diversificado que hacía poco rentable el comercio entre Buenos Aires y el Interior.

Lo otro que aparece, simultáneamente con la guerra, fue una situación política, social y militar caracterizada por la presencia de descontentos, rebeliones y lo que pareció ser un intento de volver sobre formas de organizar el poder previas a Pavón, e incluso a Caseros, como por ejemplo, el descontento del interior a la política porteña, hecho puesto de manifiesto en la rebelión federal encabezada por el General Ángel Vicente Peñaloza El Chacho.

\section{Finanzas públicas entre 1852-1862}

\section{De la Confederación}

Luego de la caída de Rosas y secesión del Estado de Buenos Aires, el gobierno federal se estableció en Paraná, sancionó la Constitución Nacional en mayo de 1853 y dio origen a un gobierno nacional que buscó sostenerse con los fondos de un Tesoro nacional formado, entre otros recursos, por 
los derechos de importación y exportación de las aduanas.

Aun cuando el artículo $4^{\circ}$ de la Constitución refiere a los recursos recaudados de los derechos de importación y exportación de las aduanas, la Aduana de Buenos Aires si bien no era la única, constituyó la puerta de ingreso y egreso de todos los bienes y servicios adquiridos y producidos por las provincias Unidas del Río de la Plata; y por lo tanto, la única en condiciones de generar los ingresos necesarios para cumplir con los alcances del mencionado artículo. Por ejemplo, en 1851 la Aduana del puerto de Buenos Aires proporcionó una renta de 84 millones de pesos corrientes (p.ctes) o 4 millones de pesos fuertes (\$F). Frente a estos guarismos, las demás Aduanas del interior no podían competir, lo que induce a pensar que el gobierno federal de la Confederación nació como una opción de organización nacional, económica y financieramente inviable.

Evidente debilidad que explica, porque Urquiza impulsó distintas políticas para neutralizarla, aun cuando eso no evitó el receso de Ejecutivo Nacional en diciembre de 1861. Se destacan entre esas políticas, la creación del Banco Nacional, la sanción de leyes que impulsaron gravámenes (v.g. la Ley de Derechos Diferenciales), la toma de deuda de fuentes de financiamiento nacionales y extranjeras.

El Banco Nacional comenzó a funcionar el 3 de febrero de 1853 como entidad de naturaleza heterogénea, con funciones de emisión y descuento, de Contaduría y Tesorería de la Nación. Compitió con la Casa de Moneda de Buenos Aires por medio de una política de descuentos más liberal pero fracasó, cerrando sus puertas el 26 de septiembre de 1854.

La ley de derechos diferenciales - gravó con un impuesto menor a los productos que ingresaran por los puertos de la Confederación, y con otro mayor a los que lo hicieran por la Aduana de Buenos Aires -, iniciativa para revertir el resultado económico deficitario de su balanza comercial - por la Aduana del puerto de Rosario se exportaron bienes por unos 14 millones de pesos e importaron otros por 22 millones de pesos.

Con relación a la toma de deuda, $\mathrm{Ur}$ quiza delegó la tarea en José Buschenthal, financista montivideano que conociendo las carestías de la Confederación, fue el primero en prestar 225.000 pesos fuertes al interés usurero del $16 \%$ anual, contra entrega de títulos admitidos por las aduanas de la Confederación por su valor nominal, independientemente de su valor real. Buschenthal gestionó en Europa un empréstito por 5 millones de pesos fuertes, ofreciendo en garantía la recaudación de las aduanas y el pago de un interés anual del 6\%, buscó inversores para la construcción de un ferrocarril de Rosario a Córdoba, y promovió la fundación de un banco de crédito e emisión. Las gestiones de Buschenthal fracasaron junto a las que luego se les encargó a los franceses Arístides Trouvé-Chauvel y Antoine Dubois.

La demanda de recursos para el sostenimiento del conflicto con Buenos Aires y los insuficientes fondos públicos; obligaron al gobierno de Paraná a optar por financiamiento externo que ofreció el Brasil, conduciendo el proceso político a un nuevo pacto con la política exterior brasileña o política del patacón. 
El empréstito con el Brasil se acordó el 27 noviembre de 1857, ascendió a la suma de 300.000 pesos fuetes $(\$ F)$, y significó el comienzo de una nueva dependencia con el Brasil, aun a pesar de la evidente rivalidad que existió desde la misma creación del Virreinato del Río de la Plata; quien una vez más buscó incidir en los destinos de los países del Plata.

Días antes de la firma del acuerdo con el Brasil, el 26 de noviembre de 1857, se presentó en Paraná Ireneu Evangelista de Sousa (Barón de Mauá), propuesto por José de Buschenthal como la persona idónea para operar un banco de emisión y crédito. Entidad privada que abrió sus puertas en la ciudad de Rosario el 2 de enero de 1858, bajo la denominación de Mauá \& Cia.

El Barón de Mauá impulsó una política monetaria sustentada, en la lucha contra la moneda boliviana circulante, y el establecimiento de una convertibilidad, un patrón al que se ajusten todas las monedas que circulan en la Argentina, con el fin de actuar sobre el papel moneda corriente, sostén principal del Estado sesionado de Buenos Aires. Fin que no es tal si se tiene en cuenta que el propio Mitre convino en considerar al papel moneda como un cáncer, lo mismo que su Ministro de Hacienda, Norberto De la Riestra, al asegurar que Buenos Aires no prosperó por su moneda sino a pesar ella.

Independientemente de lo retórico del caso, la estrechez financiera de la Confederación resultó más que evidente; es decir, mientras los ingresos de la Confederación en 1855 alcanzaron 1,8 M\$F (millones de pesos fuertes), los de Buenos Aires en 1850 se ubicaron en 3,1 M\$F; en tanto que los gastos de la Confederación en 1861 fueron de 3,5 M\$F, los del gobierno nacional en 1863, incluido Buenos Aries, alcanzaron los 6,8 M\$F.

\section{Del Estado de Buenos Aires}

Derrotado el régimen rosista luego de Caseros, Urquiza promovió la organización nacional sobre la base de una constitución federal, que entre otros aspectos preveía la nacionalización de los ingresos de las aduanas y la federalización de la ciudad de Buenos Aires. Como era de prever, los porteños se negaron a reconocer toda otra autoridad nacional que no fuera la del Estado de Buenos Aires, y en particular, a entregar su principal fuente de recursos: la Aduana. Situación que derivó en un enfrentamiento de casi diez años, que finalizó con el éxito de los porteños en Pavón, y generó un gasto significativo que fue solventado con emisión monetaria.

La emisión monetaria constituyó una de las características del período 1853 - 1861, los otros fueron la baja en la tasa de descuentos y el estimulo al ahorro. La fuente de financiamiento de Buenos Aires fue la emisión, tan grande y descontrolada que conforme aumentó la emisión y las especulaciones en la Bolsa de Comercio, se acentuó su devaluación debido a su inconvertibilidad - falta un patrón o moneda de referencia para precisar su valor.

Desde los tiempos de la revolución, Buenos Aires afrontó sus gastos con emisión. No obstante estos antecedentes, Velez Sarfield trazó su política bancaria a partir de la transformación de la Casa de Moneda en banco de depósito y descuentos, negándole la de instituto emisor, como medio de control.

En diciembre de 1853 creó en la Casa de Moneda los depósitos de ahorro, que obra- 
ron como fuente de financiamiento, limitando nuevas emisiones, al tiempo que también bajó la tasa de descuentos del 1 al 0,75\% mensual, entre febrero de 1852 y marzo de 1854.

En la idea de diversificar las funciones bancarias, transformó a la Casa de Moneda en Banco y Casa de Moneda de la Provincia - entidad que el 9 de noviembre de 1863 pasó a denominarse Banco de la Provincia de Buenos Aires. Si bien entre 1854-64 se obtuvo una sorprendente expansión monetaria, entre 1859 y 1861 se emitieron un total de 185.000 .000 p.ctes., por lo tanto la emisión siguió siendo la alternativa de financiamiento para la coyuntura, pero no por ello dejo de tratarse de papel moneda inconvertible.

Susana Sambuccetti confirma el valor ficticio del papel moneda al señalar que, entre 1859 y 1861, Buenos Aires emitió 135 millones de p.ctes., Mientras el valor del peso corriente en 1860 respecto de la onza de oro fue de 344 p.ctes. y alcanzó en 1862 los 409 p.ctes; el peso fuerte pasó de \$20,09 a 23,98 p.ctes.; es decir, experimentó una depreciación del $19 \%$.

En resumen, las finanzas públicas de una y otra parte dependieron del poder de captación de recursos y en este aspecto, Buenos Aires sostuvo su poder en la posesión de la Aduana, una de las causas de su confrontación con el interior, que comenzó a superarse a partir de 1862, cuando Mitre nacionalizó la Aduana de Buenos Aires.

\section{Reforma constitucional de 1860}

Luego de más de cuarenta años de enfrentamiento entre Buenos Aires y las provincias, su causa puede identificarse con la posesión del puerto; en particular, con la renta de su Aduana. Conflicto que pareció tener un principio de solución luego de la batalla de Cepeda (23 de octubre de 1859).

Se aprecia que la desinteligencias comenzaron cuando Buenos Aires se negó rubricar el Acuerdo de San Nicolás - 31 de mayo de 1852 -, que definió las bases de la organización nacional; en particular, el aporte de un porcentaje de lo recaudado por su Aduana para sostén del futuro gobierno nacional.

Aun cuando la Confederación resultó victoriosa en Cepeda y el Congreso Nacional ordenó someter a Buenos Aires por la fuerza, Urquiza optó por la negociación, que finalizaron con la firma del Pacto de San José de Flores el 11 de noviembre de 1859. El Pacto permitió el ingreso de Buenos Aires a la Confederación y la revisión de la Constitución Nacional de 1853. La convención porteña que revisó la Constitución propuso reformas, en su mayoría de forma. No obstante, su reclamo se focalizó en exigir a la Nación la garantía del presupuesto de Buenos Aires del año 1858 al verse obligada a ceder su Aduana, y eximir al Banco y Casa de Moneda de la Provincia de Buenos Aires de todo impuesto nacional.

Las reformas propuestas fueron aprobadas pero esto no significó la finalización de la confrontación. Una serie de acontecimientos ocasionaron la ruptura de relaciones entre Buenos Aires y la Confederación, que decidieron dirimir sus diferencias por medio de las armas. Del enfrentamiento en Pavón, Mitre resulta vencedor. Luego de ser nombrado Encargado del Poder Ejecutivo nacional, proyectó su autoridad e impuso su poder coercitivo al resto de las provincias, 
reunió en mayo un Congreso Nacional y fue electo presidente de la nación, cargo que asumió el 12 de octubre de 1862.

Luego de este breve relato de los acontecimientos, la letra de los siguientes artículos de la Constitución Nacional sugiere el porqué de la negación de Buenos Aires a ceder los recursos de su Aduana a la Nación.

Según la Constitución Nacional de 1853:

Art $4^{\circ}$ - El Gobierno federal provee los gastos de la Nación con los fondos del Tesoro nacional formado del producto de derechos de importación y exportación de las aduanas, del de la venta o locación de tierras de propiedad nacional, de la renta de Correos, de las demás contribuciones que equitativa y proporcionalmente a la población imponga el Congreso General y de los empréstitos y operaciones de crédito que decrete el mismo Congreso para urgencias de la $\mathrm{Na}-$ ción, o para empresas de utilidad nacional.

Art $67^{\circ}$ - Corresponde al Congreso:

$1^{\circ}$ Legislar sobre las aduanas exteriores, y establecer los derechos de importación y exportación que han de satisfacerse en ella.

Buenos Aires se opuso a la expresión de las aduanas, por cuanto entendió que significaría un mayor aporte respecto de las restantes aduanas y un perjuicio para sus finanzas públicas. Por lo tanto, el artículo $4^{\circ}$ y el $67^{\circ}$ quedaron como se expresa a continuación:

Art $4^{\circ}-$ El Gobierno federal provee los gastos de la Nación con los fondos del Tesoro nacional formado del producto de derechos de importación y exportación hasta 1866, con arreglo a lo estatuido en el inciso $1^{\circ}$ del artículo 67 , del de la venta o locación de tierras de propiedad nacio- nal, de la renta de Correos, de las demás contribuciones que equitativa y proporcionalmente a la población imponga el Congreso General y de los empréstitos y operaciones de crédito que decrete el mismo Congreso para urgencias de la Nación, o para empresas de utilidad nación.

Art $67^{\circ}$ - Corresponde al Congreso:

$1^{\circ}$ Legislar sobre las aduanas exteriores, y establecer los derechos de importación, los cuales así como las avaluaciones sobre que recaigan, serán uniformes en toda la Nación; bien entendido que ésta, así como las demás contribuciones nacionales, podrán ser satisfechas en la moneda que fuese corriente en las provincias respectivas por su justo equivalente. Establecer igualmente los derechos de exportación hasta 1866, en cuya fecha cesarán como impuesto nacional, no pudiendo serlo provincial.

Obsérvese que del artículo 4 se suprimió la expresión de las aduanas, y en su lugar se agregó, hasta 1866, con arreglo a lo estatuido en el inciso $1^{\circ}$ del artículo $67, \mathrm{y}$ se adicionó al final del mencionado inciso, Establecer igualmente los derechos de exportación hasta 1866 , en cuya fecha cesarán como impuesto nacional, no pudiendo serlo provincial.

\section{Finanzas públicas a partir de 1862}

Aun con la decisión de Mitre de nacionalizar la Aduana de Buenos Aires, los recursos aportados por los derechos aduaneros nunca fueron suficientes para cubrir las erogaciones del nuevo Estado, con una renta que no crecía al ritmo que lo hacían los gastos, sobre todo porque una parte significativa de esa renta estuvo comprometi- 
da al pago de la deuda y a cubrir los déficit sistemático en que incurrieron los distintos gobiernos.

Es decir, los gastos extraordinarios resultado de los conflictos internos, fueron durante el gobierno de Mitre de más de 3 $\mathrm{M} \$ \mathrm{~F}$ (millones de pesos fuertes), cuando el promedio de ingresos anuales osciló en los 8 $\mathrm{M} \$ \mathrm{~F}$. Esos mismo gastos durante el mandato de Sarmiento se ubicaron los $6 \mathrm{M} \$ \mathrm{~F}$ contra ingresos de unos 11/12M\$F. Montos a los que se suman los $25,5 \mathrm{M} \$ \mathrm{~F}$ que se gastaron en la guerra del Paraguay. Resulta llamativo que un gobierno, en un estado de profundas carestías, afectó esa cantidad solo para sofocar conflictos; no obstante, de no hacerlo, tal vez hubiera peligrado su supervivencia.

La situación resulta más seria si se comparan los gastos con los ingresos tributarios, los que representaron un $51 \%$ y un $42 \%$ respectivamente, lo que significa un déficit del $9 \%$. De los gastos, el $42 \%$ representó el gasto de guerra durante la presidencia de Mitre y del 30\% durante la de Sarmiento. Por lo tanto, algo más de $50 \%$ se destinó a las restantes obligaciones del gobierno, una de ellas no menor, el pago de la deuda heredada. No resulta extraño que el gobierno recurriera al crédito externo y creara el crédito público nacional como fuente financiamiento. Opción que constituyó una solución alternativa, pero con el tiempo se transformó en un imperativo para cumplir con todas las obligaciones, debido a que nunca los recursos fueron suficientes para cubrir todos los gastos.

Para superar el déficit recurrente, el Congreso evaluó la posibilidad de autorizar al gobierno nacional a emitir dinero papel; iniciativa que no prosperó, tanto por el antecedente de obrante en la provincia de Buenos Aires, como las trabas que opuso el propio Banco de la Provincia de Buenos Aires, que no quiso renunciar al monopolio de la emisión.

Al no poder emitir dinero, decidió emitir deuda, que negoció con los bancos y proveedores del Estado. Los bancos tomaron la deuda, a cambio de entregar dinero en efectivo de los depósitos de sus clientes; y los proveedores, recibieron documentos de deuda, la que consolidaron con Títulos Públicos.

En resumen, las finanzas públicas significaron un déficit recurrente, trasladable de un gobierno a otro. Es decir, mientras que el déficit del gobierno de Mitre se ubicó en los $9 \mathrm{M} \$ \mathrm{~F}$, durante el de Sarmiento alcanzó los $40 \mathrm{M} \$ \mathrm{~F}$. Si se tiene en cuenta que la deuda y los gastos de la guerra interna y externa representaron casi un $70 \%$ de los ingresos, significa que ese porcentaje estuvo comprometido antes de iniciar el año fiscal; situación que obligó a tomar nueva deuda para financiar el pasivo. Las finanzas experimentaron una mejoría durante la administración de Avellaneda, con ajuste del gasto público y la afectación de casi el $50 \%$ de los ingresos al pago de la deuda.

\section{Deuda heredada}

La deuda que la Confederación transfirió al gobierno de Mitre fue de aproximadamente unos 15 millones de $\$ F$, y la del Estado de Buenos Aires, de unos 10 millones de \$F; es decir, un total de 25 millones de $\$ F$. 


\section{El nuevo pacto fiscal}

El pacto fiscal en la Argentina de 1862 se sustentó en los alcances del artículo 4to de la Constitución Nacional: El Gobierno federal provee los gastos de la Nación con los fondos del Tesoro nacional formado del producto de derechos de importación y exportación de las aduanas, del de la venta o locación de tierras de propiedad nacional, de la renta de Correos, de las demás contribuciones que equitativa y proporcionalmente a la población imponga el Congreso General y de los empréstitos y operaciones de crédito que decrete el mismo Congreso para urgencias de la Nación, o para empresas de utilidad nacional.

La Reforma de 1860 suprimió la expresión de las aduanas y agregó en su reemplazo hasta 1866, con arreglo a lo estatuido en el inciso $1^{\circ}$ del artículo 67 , leyenda que fue anulada por la Reforma Constitucional de 1866. Obsérvese que estos artículos y otros de índole fiscal no hacen referencia expresa a recursos; no obstante, se entiende que si hace mención a gastos, implícitamente también se refiere a recursos, pero bajo la expresión: fondos del Tesoro nacional formado del producto...

La decisión de otorgar a la Nación la percepción de los derechos aduaneros atenuó los desencuentros entre Buenos Aires y el Interior, también obró como fundamento para la nacionalización de la Aduana de Buenos Aires. Hecho que para Isidoro Ruiz Moreno significó la conformación federal o unitaria de la vida política argentina, por sobre el enunciado del artículo $1^{\circ}$ de la Constitución Nacional; es decir, la Nación Argentina adopta para su gobierno la forma representativa republicana federal...
Desde siempre la Aduana de Buenos Aires constituyó la principal fuente de recursos de Buenos Aires; sin embargo, desde el 10 de octubre de 1862 pasó a proveer a los gastos de la Nación, bajo la concepción de un Estado nacional sustentado en el control total de los recursos y expresión de un régimen fiscal centralizado.

Tal vez la concepción de un Estado nacional y régimen fiscal centralizado no fue algo premeditado sino el resultado de las circunstancias que se sucedieron desde 1810. En su momento la revolución se sostuvo con los recursos que provenían de las minas de plata del Potosí y otros gravámenes; pero cuando el Alto Perú se perdió, la Aduana de Buenos Aires se constituyó en la única fuente de financiamiento; que nunca recaudó lo suficiente para proveer a los gastos de todo el territorio que pretendió controlar.

Ese estado de necesidad, llevó a las distintas administraciones gubernamentales a generar recursos por medio de la confiscación, la emisión y la toma de empréstitos. Por ejemplo, el rivadaviano de 1824 que generó una deuda de 2.618.000 libras, del millón de libras esterlinas originariamente acordado en 1824.

A la falta de recursos se sumó el decaimiento del flujo comercial del interior, consecuencia del reemplazo del régimen colonial por otro con centro de gravedad en los recursos generados por la Aduana de Buenos Aires, lo que motivó un reclamo ininterrumpido hasta 1862. La decisión de Mitre de coparticipar los recursos de la Aduana de Buenos Aires, significó la definición de nuevas responsabilidades, tanto para la nación como para las provincias, respecto de los impuestos directos e indirectos. 
El Estado nacional, como entidad que ejerce el monopolio de la violencia, el fiscal y monetario sobre el territorio que controla, demandó de toda una estructura estatal que Mitre construyó a partir del momento que fue nombrado Encargado del Poder Ejecutivo Nacional. La base de esa arquitectura estuvo en una estructura de organismos nacionales con sede en las provincias y la proyección del poder por medio de un Ejército organizado y conducido desde Buenos Aires.

La proyección del poder sobre el interior confrontó con el caudillo, persona perteneciente a la elite local, dotada de recursos y del carisma necesario para lograr la adhesión de la población radicada dentro de su ámbito de influencia. Para superar el caudillismo, Mitre dotó al Estado de instrumentos de control de recursos tanto de alcance nacional como local, la redistribución del ingreso de la Aduana de Buenos Aires y la disposición de un instrumento armado con alcance nacional para imponer el orden y sofocar cualquier intento de revuelta.

Desde lo fiscal se eligió continuar con una matriz política centralizada desde Buenos Aires, en un vasto territorio con realidades económicas diferentes. Con Buenos Aires bendecido con un puerto de ultramar, en contraste con el estado de orfandad en la que se encontraban las distintas regiones del interior. Situación que las condujo a luchar contra el modelo político y económico impuesto desde Buenos Aires.

Finalmente, el gran aporte del pacto fiscal constitucional fue la puesta en escena de la institución representativa del Congreso artículos 4, 44 y 67 de la ley Suprema -, como representante de los gobernados. Herramienta que a través del voto de los gravámenes tributarios permitió el sostén del Estado.

\section{Situación económica}

El desorden financiero solo fue posible superarlo con economía sustentable; aspecto que se alcanzó a partir del momento que el gobierno nacional logró imponer su hegemonía; proceso iniciado con Mitre y consumado por Roca hacia 1880.

Bartolomé Mitre inició el proceso luego del triunfo porteño en Pavón, superó la rebelión del Chacho primero y luego la de los Colorados, en pleno desarrollo de la guerra del Paraguay. Sarmiento continuó el proceso con el control del poderoso Ejército de Entre Ríos y la anulación del poder de los Taboada desde Santiago del Estero. Avellaneda desbarató la revolución de 1874, desplazando al partido Liberal e instalando al Partido Autonomista Nacional (PAN).

A la imposición del orden siguió el desarrollo económico, impulsado por los ingresos provenientes de los derechos de importación y exportación. No escapa a nadie que durante la década de 1860 la producción ovina constituyó el motor principal de economía argentina. Aportó más de dos tercios del total de las ventas realizadas al exterior, 3 de 4 ovinos existentes en el país pastaban en tierras de la provincia de Buenos Aires.

Las exportaciones de lana pasaron de representar un $10 \%$ en la década de 1840 , a un $20 \%$ en la de 1860 , y alcanzó un $50 \%$ a principios de 1880 , con un crecimiento 
estimado de las ventas al exterior del orden del $8 \%$ anual.

\section{Situación militar}

Pavón dio a Buenos Aires la posibilidad de imponer su hegemonía sobre el interior, $\mathrm{y}$ para su logro, Mitre desarrolló una campaña de cooptación coercitiva sobre la base de un ejército conformado por unidades de línea y Guardias Nacionales. Entre septiembre de 1861 y junio de 1865, el instrumento militar sufrió distintas reorganizaciones, la primera el 03 de octubre de 1862, con la creación del Ministerio de Guerra y Marina sobre la base del Departamento de Guerra y Marina de la provincia de Buenos Aires. Posteriormente reordenó el personal, tanto del que sirvió en los Ejércitos de la Confederación como en el de Buenos Aires. En enero de 1864, creó el Ejército Nacional; organización que estuvo compuesta por 6.000 efectivos, alcanzando los 25.000 hombres, a partir de la agresión paraguaya a la ciudad de Corrientes el 13 de abril de 1865.

\section{Desde Pavón a la organización del} Ejército Nacional

La campaña cooptativa coercitiva de Buenos Aires sobre el interior, se sostuvo sobre el 1er Cuerpo del Ejército porteño, constituido de unos 3.000 hombres y al mando del General Wenseslao Paunero, y los baluarte liberales de los Taboada en Santiago del Estero, del Coronel Olascoaga en Córdoba y del General Ignacio Rivas en Cuyo.

La única resistencia contundente del interior fue presentada por el General Ángel
Vicente Peñaloza (El Chacho) desde los llanos riojanos. Si bien interrumpida por medio del acuerdo de La Banderita en mayo de 1862 , las circunstancias incidieron en el surgimiento de otra etapa de inestabilidad, producto del descontento de los gobernadores, no tanto por el acuerdo en sí, sino por la resistencia al centralismo porteño que afectaba su autonomía, en particular, su restricción a la movilización de milicias y conducción de las operaciones militares.

En medio de la tensión el gobierno nacional y por medio del decreto del 10 de diciembre de 1862 dispuso el reordenamiento de Generales, Jefes y Oficiales en cuatro Planas Mayores - activa, disponible, inactiva y pasiva. Institución que estuvo integrada por todo el personal que perteneció al Ejército de la Confederación o revistado en alguno de los Ejércitos levantados por las provincias que formaron parte de ella, y no revistaron en los Cuerpos del Ejército o Divisiones de Frontera. La letra del decreto hizo visible el grado de conducción centralizada que ejerció el gobierno nacional sobre el instrumento militar, lo cauto respecto del gasto, en particular, el correspondiente a los Jefes y Oficiales que formaron parte de la plana mayor pasiva.

La esperada pacificación nacional escaló hasta degenerar en una nueva movilización federal de magnitud, que se dirigió a las provincias de Catamarca, Córdoba y San Luis y Mendoza. Frente a la nueva crisis Mitre ordenó el desarrollo de una campaña de policía y no una guerra civil por cuanto el gobierno nacional no estaba en condiciones de comprometerse en una campaña militar. Sin embargo, la campaña degeneró en una nueva guerra civil, culminando con la muerte 
del Chacho Peñaloza el 12 de noviembre de 1863. Como era esperable, al costo en vidas humanas se sumaron los costos financieros, para los que el Congreso Nacional autorizó un crédito suplementario por 1 millón p.pta., para el pago de sueldos, mantención y equipo de la Guardia Nacional movilizada.

Superada la crisis, Mitre dispuso el 26 de enero de 1864 la organización del Ejército Permanente. De la letra de los considerandos del decreto emanan las causas de su decisión, dos de índole político y una de naturaleza económica:

Que el número y la composición del Ejército de Línea debe arreglarse á las exigencias del servicio que en la actualidad tiene que desempeñar; Es decir, esas exigencias del servicio en la actualidad, pueden ser interpretado a las propias de un período de relativa paz. Que han cesado las circunstancias extraordinarias que hicieron indispensable su aumento; Es decir, fue derrotado el último alzamiento federal del interior. Que es indispensable hacer en los gastos que pesan sobre el Erario Nacional las mayores economías posibles, sin perjuicio del servicio público Es decir, minimizar el gasto militar sin comprometer la capacidad de defensa común.

La organización produjo una reducción del Ejército de Línea, de 10.200 a 6.000 hombres, aparte del mantenimiento de los piquetes fijos de Bahía Blanca, Patagones, otros puntos de la República y los indios amigos regimentados, los que no podían exceder los 600 hombres.

En particular, de su articulado resultan las siguientes consideraciones:

- El Ejército quedó organizado sobre la base de cinco batallones de infantería y la Legión Militar, por sobre un efectivo anterior de 11 batallones de infantería. Los batallones sobrantes fueron reorganizados o refundidos en los batallones existentes, lo que significó una redistribución del personal en la orgánica de los batallones que permanecieron.

- Su artículo $4^{\circ}$ especificó quienes cobrarían el sueldo íntegro. Aspecto acotado a los que formen parte de los Cuerpos del Ejército y Oficinas Militares, los Generales, Jefes y Oficiales que revistando en la Plana Mayor Activa, se encuentren desempeñando una Comisión de Servicio ordenada por el gobierno nacional, siempre que esta sea continuada y pase de un mes.

- Su artículo $5^{\circ}$ estableció el porcentaje del sueldo del que gozarán los restantes Jefes y Oficiales que revistan en las Planas Mayores Disponibles (mitad de sueldo), Inactivas (cuarto de sueldo) y Pasiva (no percibía sueldo).

- Su artículo $6^{\circ}$ determinó que aquel Jefe y Oficial que desempeñe una comisión o empleo no militar no cobrará sueldo militar, así como los que estén comprendidos dentro del artículo 6to del decreto del 10 de diciembre de 1862, pasarán a formar parte de la Plana Mayor Pasiva.

- Su artículo $7^{\circ}$ licenció a toda la Guardia Nacional del servicio de fronteras, reservando para esta tarea, solo al Ejército de Línea.

De los nueve artículos, siete estuvieron orientados a... los gastos que pesan sobre el Erario Nacional las mayores economías posibles, sin perjuicio del servicio público.

A pesar de la muerte del Chacho, la resistencia del interior no disminuyó; sin em- 
bargo, durante el año 1864 las exigencias del servicio pasaron por mantener la frontera con el indio y el poder coercitivo sobre las provincias, como medio de formación del sistema de dominio social.

\section{Organización del Ejército Nacional de Campaña}

Producido el ataque a la ciudad de Corrientes el 13 de abril de 1865, el gobierno nacional adoptó innumerables medidas de todo tipo, independientemente de su realidad financiera, lo que evidenció experiencia en la movilización de recursos para la guerra y funcionalidad de un estado nacional en formación.

La urgencia hizo que se dictaran más de treinta disposiciones militares, solo en el mes de abril, para responder a la invasión paraguaya. Las que serán enunciadas al solo efecto de poner en evidencia la capacidad en la toma de decisiones frente a la crisis, cuando el gobierno se encontró a mitad de su mandato, no disponía del consenso unánime del interior y los recursos financieros eran insuficientes.

La historiografía habla de un tiempo que medió entre la oportunidad de declaración de guerra del Paraguay y el momento que el pueblo de Buenos Aires tomó conocimiento de la noticia, y aun cuando este aspecto no constituye un objeto de análisis; lo cierto es que ese tiempo existió y el gobierno nacional lo utilizó para adoptar las decisiones necesaria para enfrentar la sorpresiva agresión. Sorpresa que no debió ser tal si se tiene en cuenta que la guerra nunca estalla de manera totalmente inesperada ni puede propagarse de repente, si cada uno de los bandos valora al otro sobre la base de lo que hace y no sobre lo que pudiera hacer, tal cual lo señala Carl von Clausewitz (1999) en su obra De la Guerra.

Aquel momento de fervor patriótico sirvió a Mitre para hacer gala de su retórica; aun cuando la frase que pronunció en aquella ocasión, utilizada por sus afectos y desafectos, no sumó nada nuevo al análisis más que a su elocuencia. Sin embargo y en medio de esas circunstancias, decretó la movilización de la Guardia Nacional en toda la República.

El Ministerio de Guerra y Marina previó todo lo necesario para concretar la movilización, entre otras, la parte con que cada Provincia contribuyó a la seguridad y defensa de la Nación. Aun cuando la Argentina dispuso de unos 160.000 hombres en capacidad de ser movilizados; solo se movilizaron unos 29.000 hombres; es decir, un 12,5\%.

Para hacer viable, rápida y eficaz la movilización, el gobierno nacional dispuso el 19 de abril de 1865 la creación de cinco inspecciones de armas, la de Salta y Jujuy a cargo del General D. Rudecindo Alvarado; la de Tucumán y Catamarca al mando del General D. Anselmo Rojo; en La Rioja y Santiago del Estero, el General D. Antonio Taboada; y en las de San Juan y Mendoza, Córdoba y San Luis, el General D. Emilio Mitre (hermano del presidente).

De la lectura de sus atribuciones y deberes se evidencia la supremacía de lo nacional por sobre lo provincial, sobre todo un cambio sustancial en las atribuciones del Gobernador, si se tiene en cuenta que desde la Colonia la movilización militar estuvo a cargo del Gobernador Intendente. 
En particular para la remonta de los Cuerpo del Ejército de Línea, el poder ejecutivo dispuso que cada provincia debiera contribuir con una cantidad de efectivos determinada, sea por alistamientos voluntarios y/o enganchados, lo que arrojó un total general de 1.750 hombres.

El reclutamiento estuvo orientado a personas entre los 18 y los 40 años de edad, y por un plazo de uno o dos años. Por el servicio los voluntario o enganchado recibirían $25 \$ \mathrm{~F}$ al momento de filiarse, otros 25 al jurar la bandera, y 100 más por cumplir su servicio de dos años; en tanto que los que se alistasen por un año, recibirían los mismos valores por filiación y jura de la bandera y $50 \mathrm{\$ F}$ al cumplir el año de servicio. De acuerdo a los valores expresados, los efectivos impuestos y el tiempo de movilización, el gasto se ubicó en los 88.100 \$F por un año de servicio, y en 175.000 \$F por dos años.

Conjuntamente con la remonta de los Cuerpos del Ejército de Línea se dispuso la movilización de la Guardia Nacional, y simultáneamente la formación del Ejército Nacional de Campaña, fijando la cantidad de 19 batallones de la Guardia Nacional de Infantería, cada uno con 500 plazas o un total 9.500 hombres.

Los meses que mediaron entre abril y junio de 1865 fueron intensos para el gobierno nacional, sea por la movilización de los recursos humanos, materiales y financieros como también porque debió mantener el despliegue de las Divisiones de Fronteras y las guarniciones fijas en cada provincia. Al mismo tiempo previó la organización del Ejército de Reserva, armado y equipado por la Nación, quedando a órdenes de los Ins- pectores de Armas en las respectivas Provincias, hasta tanto fueran llamados al servicio activo en el Paraguay.

El Congreso Nacional, frente a la situación de guerra que vivía la Argentina, sancionó la ley que autorizó al Ejecutivo Nacional a levantar un Ejército de 25.000 hombres, organizado sobre la base de la remonta del Ejército de Línea hasta el número de 10.000 hombres, y los restantes 15.000 por medio de la movilización de las Guardias Nacionales de la República.

Si bien la Ley ordenó un Ejército Nacional de Campaña de 25.000 hombres, al 30 de abril de 1865 el Ejército permanente contó con 8.715 hombres. No obstante, este efectivo se mantuvo en los lugares que guarnecía, en particular en las fronteras con el indio.

El Congreso convalidó los decretos presidenciales del 17/19 de abril 1865 que fijó la organización del Ejército Nacional de Campaña sobre la base de 19 batallones de Guardias Nacionales de Infantería y la remonta del Ejército de Línea, en un número de 1.750 hombres, a los que se agregaron, entre otras, las siguientes unidades militares:

- Los contingentes de 5.000 efectivos de caballería a movilizar por las provincias de Corrientes y Entre Ríos, o un total de 10.000 hombres.

- La Legión de Voluntarios.

- La compañía de zapadores.

- El Batallón de Estudiantes o General Belgrano integrado por estudiantes de la Universidad y demás Colegios de Buenos Aires - Mitre lo desactivó ante la necesidad de Oficiales para organizar la Guardia Nacional. 
- El Regimiento de Caballería de Línea o Escolta del Gobierno.

- El Regimientos de Caballería de Guardias Nacionales de la provincia de Buenos Aires o General San Martín, y otro por la provincia de Santa Fe.

- La creación y organización del cuerpo médico del Ejército.

\section{Consideraciones finales}

\section{Situación militar:}

Disponibilidad de un Ejército en proceso de reorganización, que se redujo de 10.200 a 6.000 hombres en enero de 1864, que al mes de abril de 1865 disponía de 8.715 hombres del Ejército de Línea, Guardias Nacionales e indios amigos regimentados desplegados en puntos fijos y en la frontera con el indio, y que a junio de ese mismo año se vio en la necesidad de organizar un Ejército Nacional en Campaña de 25.000 hombres y alistar otro de Reserva de 6.000 hombres.

2. Situación económica-financiera del gobierno de Mitre al inicio del mandato:

a. Mercado monetario diversificado, discrecional y falto de regulación. Aspecto que afecto al comercio de Buenos Aires con las provincias.

b. Deuda pública estimada en unos 28 M\$F (15 M\$F de la Confederación 10 el Estado de Buenos Aires, mas $3 \mathrm{M} \$ \mathrm{~F}$ por imposición del orden) y asumida por el gobierno de Mitre.

c. Gastos que superan a los ingresos nacionales. Dos terceras partes del presupuesto, antes del inicio de cada año fiscal, debían ser destinados al pago de la deuda públi$\mathrm{ca}$, frente a un ingreso promedio anual de unos $8 \mathrm{M} \$ \mathrm{~F}$. Se hubieran necesitado los 6 años de mandato presidencial para saldar la deuda, afectando unos 5,2 M\$F por año y dejando 2,8 M\$F para gastos de la administración e inversión pública. Algo que no fue tan así, teniendo en cuenta que a partir de abril de 1865, la Argentina asumió el nuevo compromiso de ir a la guerra del Paraguay, lo que significaría una erogación estimada de unos $25 \mathrm{M} \$ \mathrm{~F}$ en cinco años (1865-1870), recursos que no disponía, pero que igualmente debió financiar.

d. Armado de un aparato estatal de alcance nacional inexistente.

e. Balanza comercial deficitaria (EX IM) que fue corrigiéndose conforme se incrementaron los saldos exportables de la lana.

f. Impuestos a las exportaciones que por la Reforma de 1860 dejaban de ser parte de la renta nacional a partir del 31 de diciembre de 1965, a tan solo nueve meses de inicio de la guerra del Paraguay.

\section{Resumo}

O texto em negócios gerais com a análise da situação financeira, econômica e militar entre 1852 e o início da guerra no Paraguai. A análise é uma situação que poderia muito bem ser descrita como de mau agouro para a Argentina parti- 
cipar na guerra. A hipótese é validada através da análise dos principais acontecimentos financeiros e militares que caracterizaram o período em estudo. $\mathrm{O}$ argumento começa com a apresentação das demonstrações financeiras da Confederação e do Estado de Buenos Aires entre 1852 e 1861, continua com a definição de dívida que gerou e transmitida ao governo nacional em 1862. Ele avalia o alcance da reforma constitucional de 1860 e seu impacto sobre o pacto fiscal que começou em 1853 e o estado da economia sobre a sua importância para as contas nacionais. Finalmente, a situação do instrumento militar é exposta de Pavón para a organização da Campanha do Exército terminou penhorar no teatro do Paraguai.

Palavras-chave: Situação econômica. Situação militar. Estado nacional.

\section{Abstract}

The text in general deals with the analysis of the financial, economic and military situation between 1852 and the beginning of the war of Paraguay. The analysis is a situation that could well be described as inauspicious for Argentina to participate in the war. Hypothesis is validated through the analysis of the main financial and military events that characterized the period under study. The argument begins with the presentation of the financial statement of the Confederation and the State of Buenos Aires between 1852 and 1861, it continues with the definition of debt that generated and transmitted the national government in 1862. It assesses the im- plications of the constitutional reform of 1860, its impact on the fiscal pact that began in 1853 and the state of the economy on its importance for the national accounts. Finally, the situation of the military instrument is exposed from Pavón to the organization of the National Army pawning campaign that ended in the theater of Paraguay.

Keywords: Economic situation. Military Status. Nation state.

\section{Referencias}

CLAUSEWITZ, Carl von. De la Guerra. Tradução de Michael Howard y Peter Paret. España: Ministerio de Defensa de España, 1999. (1838).

RUIZ MORENO, Isidoro J. La reforma constitucional de 1866. Buenos Aires: Macchi, 1966. 